\title{
MODELLING OF THE CASH FLOW OF BABY LOANS - A NOVEL APPROACH
}

\author{
Attila Grósz - Zsombor Sárosdi - Gergely Biró - Péter Molnár ${ }^{1}$
}

\begin{abstract}
Baby Loan is a new loan product in the Hungarian market, a special form of subsidy to boost childbearing willingness. However, due to this feature of the product, banks have to face a new challenge, as the expected cash flows depend on demographic factors. As opposed to contractual cash flows, banks need actual expected cash flows for risk management and other pricing reasons.

Banks have modelled the cash flows they expected in addition to contractual repayment to date, however, such models are typically based on past data and experience. In this writing, we describe an alternative method, which can be used in practice and has already been successfully applied in the insurance sector. Moreover, it is easy and understandable enough for banks to incorporate it into their daily operation.

Another fundamental element of this method is the Monte Carlo simulation, by means of which, using the data provided by the Central Statistical Office, the number of unborn children, the timing of individual births or the divorce rate can be estimated. Based on the data above, an estimated cash-flow and amortisation profile, which can be used in the fields of risk management, business and accounting, can be established.
\end{abstract}

JEL codes: $\mathrm{C}_{4}, \mathrm{C}_{5}, \mathrm{C} 6, \mathrm{G}_{2}$

Keywords: baby-expecting, demography, birth, the number of children, divorce, cash flow, cash flow modelling, fair value, IFRS9, actuary, Monte Carlo simulation, ALM

1 Attila Grósz, senior manager, Ernst \& Young Tanácsadó Kft. E-mail: attila.grosz@hu.ey.com. Zsombor Sárosdi, advisor, Ernst \& Young Tanácsadó Kft. E-mail: zsombor.sarosdi@hu.ey.com. Gergely Biró, manager, Ernst \& Young Tanácsadó Kft. E-mail: gergely.biro@hu.ey.com.

Péter Molnár, senior manager, Ernst \& Young Tanácsadó Kft. E-mail: peter.molnar1@hu.ey.com. 


\section{INTRODUCTION, THE PROBLEM}

The Baby Loan is a lending transaction based on Government Decree 44/2019 on baby-expecting support in the framework of which the debtor is eligible to use various subsidies during the term of the loan, which can range up to 20 or 23 years. The essence of the form of subsidy is that the debtor (more specifically, debtors are eligible, as only married couples can apply for it, providing further criteria are met) is eligible to apply for interest-rate subsidy or child-bearing loan. The main point of interest-rate subsidy is that the transaction carries interest at a preferential rate as of the application. In the case of personal loans, this rate is more favourable than the market rate. Moreover, if the married couple has at least one baby within 5 years after the application, the loan becomes interest-free. If the married couple fails to have a baby within 5 years, the amount they used as interest rebate has to be repaid and market terms will apply to the loan. In practice, child-bearing loan mean partial or full loan remission, which is actually a partial or full prepayment by the state. In the case of the first child, they are not eligible for this kind of prepayment. After the second child, $30 \%$ of the actual exposure is prepaid, while after the third child, $100 \%$, i.e. the total amount is prepaid by the state.

Based on the short and non-exhaustive description of the product parameters and detailed rules, it is apparent that it is an exceptional credit product. The product involves not only two, but three participants. The debtor(s), the bank and the state. Although there has been a similar product in the market, the new element is that the amounts to be paid by the state and the debtors are not known in advance, they depend on one or more demographic events.

Why is it a problem that the bank is not fully aware of the timing and volume of the cash flows? Basically, it is problematic for the bank from two aspects: on the one hand, it is a risk management issue, on the other hand, it is an accounting problem.

Regarding risk management, banks consider the volume and timing of all interest and capital cash flows important, especially when they are fixed-interest exposures, as they bear interest rate risk. In compliance with normal market practices, banks combine fixed-interest transactions with hedges, typically interest rate swaps (IRSs), thus reducing the risk of an increase in the cost of resources owing to a possible growth in interest rates, with unchanged lending rates. Of course, in addition to interest rate swap, there are other techniques, as well. One of the tried-and-tested methods is when the bank finances the loan from fixed resources. However, such resources are not always directly linked to the financing of loans, therefore monitoring and measurement of the interest rate risk are only portfolio-based. 
At the same time, the above-mentioned approaches have a common feature: in order to be able to quantify and cover the interest rate risk, banks have to know based on what capital exposures fixed interest rates will be calculated, i.e. what will be the capital cash flows in the future and what the capital amortisation of the loan transaction will look like. Nevertheless, it is not fully known at the start of the loan and during the term of the loan.

To sum up the above, if a bank intends to manage its risks, in particular the interest rate risk in the banking book, efficiently, it is necessary to know the expected (and not the strictly contractual) cash flows of loans.

Regarding accounting, due to the specific features of the product, banks have to face a problem: the product has to be measured at fair value in their banking books. In this respect, views differ in the market, but most arguments are in favour of this procedure in accordance with the IFRS rules. Fair value measurement is needed because of interest calculation, which is carried out as follows:

Interest $=$ the average of the 5-year Government Debt Management Agency (ÁKK) yield of the past 3 months $\times 130 \%+2 \%$

As a result of the multiplication with $130 \%$ in the formula above, the change in market yields always has more powerful effect on the client's interest rate, which is practically similar to leverage. Fundamentally, fair value measurement is not a problem to banks, but calculation requires the recording of expected cash flows with appropriate certainty. In the course of fair value measurement, in addition to the prediction of cash flows, another difficulty may be the calculation of the yield curve and other components used for discounting. However, this essay does not cover this problem.

In view of the above, the estimation of expected cash flows is indispensable for risk management and the preparation of accounts. In this respect, banks act prudently if they apply a well-founded methodology that is based on professional estimates to the least possible extent. Of course, the estimate made for the purposes above can be used in other areas, as well, for example for internal transfer pricing or business planning for different terms.

\section{PREVIOUS MARKET PRACTICES AND THEIR PITFALLS}

The loan appeared as a new product in the market, therefore its future payments, the changes of the related risks and even the maturity itself depend on demographic variables. Pursuant to the Government Decree 44/2019 on baby-expecting support, banks have to find their own solutions to the prediction of the term of the loan portfolio. 
Based on our previous experience, we emphasise that more than one good solutions exist, as in each case, the size, complexity of the financial institution and the relevant cost-benefit principle have to be considered. At the same time, for the purpose of illustration, we will present the deficiencies through two examples from the market.

\subsection{Modelling of the exposure and cash flow of the Baby Loan by means of a deterministic scenario set}

In our first example, prepared "most likely" scenarios selected on professional basis were used for modelling the term of the loan. The weights for the scenario set are also professionally determined, supported by past snapshot data, i.e. "stock" type data.

In the case of this kind of approach, 3-5 scenarios are used. Usually, the outcomes of the scenarios do not cover the whole possible sample space, therefore the applied weights cannot be appropriate either. A typically omitted demographic event is the occurrence of divorce. From a professional viewpoint, it would seem an illogical step to get officially divorced and not to take financial advantage of the Baby Loan. Regardless of the above, we cannot ignore the fact the number of marriages was exceptionally high in 2019 compared to previous years. We do not have any information about the longevity of these marriages, but our assumption regarding their expected length will be detailed in the part where the estimates of demographic parameters are descried.

Deterministic scenarios also determine the number of children as well as their date of birth. The model may be even more inaccurate if they try to grasp the differences arising from age by the professional correction of weights. As in the case of Baby Loans, we do not have a product-specific time series of appropriate length, therefore we have no available data on the cumulative professional inaccuracies included in the model.

Based on the above, the main weaknesses of the model are its static character and the significant proportion of missing trajectories. The latter problem could be solved by recording even more deterministic scenarios, however, it would substantially increase the manual labour required, while the relevant weights should still be determined and regularly reviewed by banking experts. Furthermore, this approach does not provide an opportunity for the fast incorporation of the bank's own observations. The conclusions drawn on the basis of internal data would require the extensive revision of detailed parameters on each occasion.

As we explain later in our essay in connection with our own approach, based on age group data, the highest possible coverage of the sample space can be ensured 
with the involvement of the least manual labour (and the resulting human errors), where weights do not need to be determined by professionals, as they are implicitly generated by the distribution.

\subsection{Modelling of the exposure and cash flow of the Baby Loan by means of a single professional scenario}

In the case of the other professional approach, the financial institutions which apply this other methodology use a single scenario, a professional trajectory curve as a starting point. Compared to the previous approach, its advantage is that a single curve is supposed to include all outcomes and, based on expected global situations and the existing knowledge, it seems to be the likeliest professional composite outcome.

A further benefit of the method is that its reweighting is simple and fast. Experts simply divert the curve towards the likeliest new composite outcomes. Without back-testing, the inaccuracy of the model is unknown. At the same time, the simplicity of the method is one of its main drawbacks, as well: the results are based on high-level professional subjectivity. Based on the baseline data, the results cannot be objectively reproduced for third parties. In addition, due to the aging and structural change of the portfolio, it is becoming more and more difficult to concentrate the scenario applicable to the entire portfolio and the relevant trajectory in a single scenario.

As a result, there is an increase in key person risk, the relevant model risk and the operational risk, which are all considered as tolerated risks that have to be reduced in the case of financial institutions of higher complexity. Consequently, in our view, it is worth investing energy into a shift towards a more sophisticated approach compared to this model, i.e. we assume that improvement and development based on the cost-benefit principle is possible even in the event of diversion from this model.

\section{A NEW APPROACH}

Initially, in order to face the challenges of modelling the Baby Loan, the idea of the involvement of actuaries came up only when the demographic parameters, which the banking sector had not used before, were being estimated. Namely, the statistical repertoire needed for the Baby Loan is very similar to the one used for pricing and evaluating birth insurance schemes. Although such insurance schemes are not too common (if they exist, they rather tend to be part of gen- 
eral health insurance packages or group coverage), but individual birth insurance schemes are even available in Hungary.

It quickly became evident that the valuation of Baby Loans can be significantly improved by not only our demographic knowledge, but also by our cash flow modelling practice, which has been typically used on the insurance liabilities side so far, and by applying stochastic demographic models used, inter alia, for the pricing of reinsurance contracts.

\subsection{The actuarial practice of cash flow modelling}

Traditionally, in the risk management processes of the insurance sector, provisions had been in the focus until the introduction of Solvency 2 (basically, a capital adequacy framework equivalent to Basel III). This system was based on cash flow estimation, while, until the introduction of the IFRS9, in the case of the banking sector, the IAS39 did not require the recording of the total cash flow of the transaction for the recognition of impairment losses, as it was necessary only when there was objective evidence.

The methodologies of insurance companies to establish so-called technical provisions for insurance risks have a history of several centuries. For example, the basics of the correction of negative provisions established for acquisition costs related to new business (the so-called "Zillmering"2), which basically means the statement of activated acquisition costs as negative liabilities instead of implicit assets, was laid down by August Zillmer, a German actuary, in 1863(!). This method is still an established practice in a practically unchanged form at several Hungarian insurance companies. The methodology of another provision established for the so-called IBNR (Incurred But Not Reported) damages, which is the most frequently used methodology nowadays, was developed in $1934{ }^{3}$

When calculating provisions, future payments $(E[K])$ and (possibly) expected revenues $(E[B])$ are usually estimated in a way. The difference of these amounts equals the size of risk buffer to be generated in the balance sheet $(E[K]-(E[B])$.

For a long time, the highly abstract mathematical orientation of actuaries, the ultimate risk managers of the insurance sector could ensure the estimation of both revenues and expenditures, i.e. basically the cash flows of transactions, by means of closed formulas, recorded in function-like form, without requiring too much

2 https://en.wikipedia.org/wiki/Zillmerisation.

3 Tarbell, Thomas F. (1934): "Incurred But Not Reported Claim Reserves." Proceedings of the Casualty Actuarial Society. Vol. XX, 275.Proceedings of the Casualty Actuarial Society. Vol. XX, 1934, p. 275. 
calculation. In addition, simplification was also made possible by the fact that, even in the case of long-term saving products, the liabilities recognised by the insurance companies in their books (insurance technical provisions) were simply equal to the all-time account value of the client

Fundamentally, by the 1990s, several phenomena generated demand for more sophisticated cash flow modelling in the field of insurance risk management:

1) as life insurance is long-term business, the effect of certain parameters on the earnings cannot be accurately established by applying simple, heuristic methods

2) in the banking sector, assets and liabilities "are treated separately", while regarding life insurance, there is a direct link between assets and liabilities on the level of the contracting parties, which is a challenge in the accurate estimation of future: cash flow on the liability side affects the cash flow on the asset side, and vice versa.

3) from the very beginning, already before it got its name, life insurance included more exotic embedded derivatives. The well-known standard "endowment"4 consists of a great variety of the most exotic guarantees and options. Some examples include the following:

a) Guaranteed yield (so-called technical interest) on the account value built up from ${ }^{5}$ a part of the paid premiums is credited periodically and continuously.

b) guaranteed maturity amount upon maturity (term)

c) guaranteed "repurchase price", i.e. exercise price or surrender value irrespective of the performance of the underlying assets concerning a minimal part of the all-time account value of the client known in advance (which may even increase during the term). Based on the above, the client has a put option against the insurance company.

d) repayment of a considerable part (80\%-90\%) of the annual yield over the guaranteed yield (the so-called "bonus") to the clients, then the automatic increase of this bonus with the interest consisting of the originally guaranteed rate of yield (the so-called "ratchet"), increasing the guaranteed maturity service as well as the guaranteed surrender value.

4 The endowment pays a contractual amount in the event of death during its term or upon maturity.

5 In the insurance sector, all client-side cash flows are called premium, e.g. the deposits paid for saving products. 
e) paid-up option; in fact, it is an embedded swaption, when the client is obliged to invest their future payments at a fixed interest rate, but they are also entitled to withdraw for a fixed fee

f) Guaranteed Insurability Option - GIO.

It is perfectly obvious that the measurement of the substantially high number of the aforementioned guarantees of often significant weight is an extremely complex task. Actually, apart from analyses published in scientific articles, there was no serious practical attempt to measure these values for decades. As these risks were measured, no serious hedge could cover them, therefore almost all larger insurance companies had these exposures as so-called "unhedged exposures".

By the 1990s, it became obvious due to the spread of personal computers and the multiplication of their computing capacity that further adherence to these old formal practices and simplifications would lead to a specific competitive disadvantage for those market participants who were unwilling to change.

The first liability cash flow modelling software available on PC appeared: Bacon \& Woodrow Prophet or Tillinghast TAS. Due to such software, pricing, which had been operating with completely closed formula, as well as the methodology for the valuation of reserves and portfolios could make a quantum leap. As a result, product innovation was not prevented by the barriers created by closed formulae anymore, but rather by the need for the development of IT systems.

Due to significantly increased computing capacity and the development of the modelling toolkit, by the end of the 199os, insurance companies applied the contract-level projection of monthly, probably weighted cash flows instead of models written on "checked paper". At several insurance companies, such models were evaluated in a stochastically, by multiple interest rate paths as well as by the Monte Carlo simulation.

Initially, in addition to the areas of the usual financial projections and product pricing, it was applied in ALM in the 1990s. In spite of this fact, the process is still characterised by considerable simplification. Instead of appropriate risk measurement and management, insurance companies still prefer the avoidance of this method.

Interestingly, despite complex models on the liability side, modelling of the asset side at a similar level has not become established practice at Hungarian (life) insurance companies. The main reason for this is that, in spite of exotic embedded guarantees, the asset side of Hungarian insurance companies consists of primarily "not too exciting" government securities or unit-linked asset funds. 


\section{THE ESTIMATION OF THE EXPECTED VALUE BY MEANS OF THE MONTE CARLO SIMULATION ${ }^{6}$}

Making different statistical estimates based on simulations is not a novel method, inter alia, János Neumann already dealt with it in the 1940s. Neumann was the first to run Monte Carlo simulations on a digital, programmable computer (the ENIAC) 7 . A new boost to their application and extensive spreading has been given by increased computing capacities to date.

Monte Carlo models are stochastic simulations, which mean that, fundamentally, if we make a simulation with the same input several times, the final result is not the same. If the outputs are not deterministic, unwanted differences may arise in practice, e.g. the analytical parity of the accounting of fair value calculation is changed or causes or the auditor may have problems (the so-called SL - GL difference) or they may even exceed a certain audit materiality level.

In addition, non-deterministic outputs may lead to legal difficulties, as well; in Germany, a leading actuary consultancy firm had to "dumb down" healthcare risk assessment algorithms based on fuzzy logic and chaos theory almost a decade ago, because in court cases, courts could not cope with a characteristic of scoring models according to which the same input did not guarantee the same output.

Of course, the modelling of the Baby Loan is a much simpler algorithm, but the aforementioned difficulties also arise, as, in many cases, the methodology of neither the accounting, not that of the supervisory authority and not even that of external auditors are prepared for the phenomenon above.

Beyond bringing the field of accounting and the auditor to their senses, the problem can be tackled and should be tackled in several ways.

Basically, two tasks have to be distinguished:

1) Supposing that other parameters remain unchanged, we would like to get deterministically the same output data from the same input data.

2) In general, we would like to reduce "simulation noise"; more specifically, we aim to decrease variance.

In the following chapters, we will write a few words about this aim.

6 In this chapter, we partly rely on an article that was published in Statisztikai Szemle (Hungarian Statistical Review) in June 2012: KeHL, DÁNIel (2012): Monte-Carlo módszerek a statisztikában [Monte Carlo Methods in Statistics], in Statisztikai Szemle 9o(6), June, http://www.ksh. hu/statszemle_archive/2012/2012_06/2012_06_521.pdf.

7 https://permalink.lanl.gov/object/tr?what=info:lanl-repo/lareport/LA-UR-88-9068. 


\subsection{The estimation of the expected value}

The estimation of the cash flows of the Baby Loan is looking for an expected value whose formal recording is equivalent to integration. If the probability density function of $X$ random variable is indicated by $g(x)$, the expected value of $h(x)$ transformed random variable is the following:

$\mu=E[h(x)]=\int_{-\infty}^{\infty} h(x) g(x) d x$

Understandably, a random sample take from $X$ distribution and the average calculated on the basis of the function above give the unbiased estimate of $\mu$ if $n \rightarrow \infty$ :

$\hat{\mu}=\frac{1}{n} \sum_{i=1}^{n} h\left(X_{i}\right) \rightarrow \mu$,

where $X_{i}$ indicated the random variable belonging to sample unit $i$.

\subsection{The reproducibility of the results of the simulation}

As it was mentioned in the introduction, normally, in the course of Monte Carlo simulation, we do not get the same outputs if we repeatedly carry out the simulations with unchanged inputs. Another problem might be caused by the fact that the quality of the random number generating algorithms of different programme languages and architectures might significantly differ. In the past, exactly the random number generating algorithms of MS Excel received some justifiable criticism. $^{8}$

If our aim is that the Monte Carlo model should produce consistently the same results on each platform, we should generate the random number sample of appropriate size (and quality) in advance and store it. We need (at least) one random number at each stage of the CF projection and for each contact. In the case of a stock of 10000 , over a period of about 280 months, we already use 2.8 million random numbers and this is only one stochastic scenario, which means a pregenerated random number of 280 million in the case of 100 simulations. The storage need of this amount is for double-precision floating-point value (sized 8 byte) is about 2.1 gigabyte!

8 For further information see: http://www.pucrs.br/ciencias/viali/tic_literatura/artigos/planilhas/ gmelard_csda23.pdf. 
Obviously, this is problematic even if a large capacity backing store is available. There might be two solutions: according to the first one, fixed random seeds can only be used in the case of the same architecture, where always the same (pseudo) random numbers are generated in the case of the simulation. According to the second procedure, one of the methodologies described in the following chapter is traced back to the random numbers used in the simulation.

\subsection{Reducing the simulation noise}

In the course of modelling, we aim to predict the expected value as accurately as possible, with the least possible variance, irrespective of whether we use a pregenerated set of random numbers or not.

The variance of the Monte Carlo estimate depends on the number of scenarios, the shape of the $g(x)$ probability density function and the number of the generated random scenarios. Based on the above, variance can be simply reduced by increasing the number of random samples, but this method is very computeintensive: indicating the number of simulations with $n$, according to the central limit theorem, variation decreases only at $o(\sqrt{n})$ speed. In other words, the number of scenarios always have to be increased by at least hundred times to decimate variation. On the other hand, several scenarios result in the significant increase in run-time: the evaluation of a stock consisting of 10000 contacts along 100 stochastic scenarios is equivalent to the deterministic evaluation of 1 million contracts.

In view of the above, the convergence of the Monte Carlo method is very slow, therefore there is a justified need for the reduction of estimation errors by other methods. Fortunately, several methods exist for this:

1) importance sampling,

2) stratified sampling,

3) control variates,

4) antithetic variables.

We will present the last three methods which we have already partly used in practice. 


\subsubsection{Stratified sampling ${ }^{9}$}

The essence of stratified sampling is that it divides the distribution function of the estimated random variable into homogeneous strata and takes samples within these strata of small subvariance in proportion to the heterogeneity of the given stratum. For example, if we want to calculate the

$\int_{0}^{1} f(x) d x$

integral with the Monte Carlo simulation and we know that the function is nearly constant within the $[0 ; 1 / 2]$ interval, it may be enough to generate only one sample unit from that interval, all the others can be generated from the $[1 / 2 ; 1]$ interval of larger variation.

In general, the method is as follows: $\Omega$ sample space is divided into $\Omega_{1}, \ldots, \Omega_{J}$ disjoint partitions in a way that $\cup_{j=1}^{J} \Omega_{j}=\Omega$. These partitions are called strata. $j$ (pieces) of samples are chosen from the $j$ stratum. Based on the average of the samples taken from each stratum, a conditional expected value is estimated, i.e.

$\widehat{\mu_{k}}=E\left[X \mid \Omega_{k}\right]$.

The expected value is estimated on the basis of the total expected value theorem, i.e. if the probability of stratum is $p_{j}$ marked by $j$.

$\hat{\mu}=\sum_{k=1}^{J} p_{k} \cdot \widehat{\mu_{k}}$.

The disadvantage of the method is that the probability of the strata has to be known. At the same time, the Monte Carlo model can provide a satisfactory estimate. If the model is run on a scenario number and the result is reasonably thought, to reflect real distribution, we can get both the homogeneous groups and the probabilities of the strata created from those groups. However, it is highly recommended to review this from time to time.

In the literature referred to, the choice of sample unit numbers belonging to the strata is exhaustively discussed. In terms of the Baby Loan, the application of this method should be considered according to the cost-benefit principle again. We would like to mention a plausible implementation. Namely, the probability of the first child not being born before the 6oth month is easy to get. Practically, the variation of this scenario is zero, as the bank receives the cash flow at a reduced rate,

9 https://www.math.arizona.edu/ tgk/mc/book_chap5.pdf. 
while later at market rate (we assume that interest rates and divorce are calculated deterministically). Consequently, it is enough to generate one such scenario and weight its cash flow with the calculated probability. The other $N-1$ scenarios are generated in a way so that at least one child could be born prior to the 6oth month. Based on the above, we can calculate with two strata. The variance has been reduced by getting more sample units from the stratum of larger variance.

\subsubsection{Control variates}

The methodology of control variates can be used if the $(h(x))$ expected value of a numerical model of an unknown $E[Y]$ expected value applied to a given $X$ random variable can be estimated with a simpler $g^{\star}(X)$ model (the so-called 'control variate'), as well, where:

$E[Z]=g^{*}(X)$

is the known expected value. In this case, the unknown $\left(m_{Y}\right)$ expected value can be calculated as follows:

$m_{Y}=m_{(Y-Z)}+E[Z]$,

i.e. corrected by the expected value of the differences estimated by sampling. It is reasonable that the variance of $m_{(Y-Z)}$ is:

$m_{(Y-Z)}=\frac{\operatorname{Var}[Y-Z]}{n}=\frac{\operatorname{Var}[Y]+\operatorname{Var}[Z]-2 \operatorname{Cov}[Y, Z]}{n}$.

In this case, if the $Z$ random variable correlates positively with the $Y$ variable and:

$[Y, Z][Z]$,

$\operatorname{Var}\left[m_{Y}\right]$ decreases. It is only worth if the expected value deriving from the $g^{\star}(X)$ model (or its estimate) is available. In the case of modelling Baby Loans, this technique can rather be used for improving the quality of pre-generated random numbers.

\subsubsection{Antithetic variables}

$X$ and $Y$ are random variables. Their joint variance is determined by the amount of their variance and the degree of covariance:

$\operatorname{Var}[X+Y]=\operatorname{Var}[X]+\operatorname{Var}[Y]+2 \operatorname{Cov}[X, Y]=\operatorname{Var}[X]+\operatorname{Var}[Y]+2 \rho_{X, Y} \sigma_{X} \sigma_{Y}$ 
The joint variance is lower than the amount of subvariances if $\rho_{X, Y}$ correlation coefficient is negative. In the course of the simulation, if we use random variables where covariance is negative, joint variance can be reduced compared to the case in which random variables are not correlated. Basically, this is the basic idea behind the method of antithetic variables (antithetic pairs or variables).

In the Monte Carlo simulation, estimate of the sought-after expected value will be some kind of function of the $U(0,1)$ evenly distributed expected random variables (random numbers are generated from this distribution):

$\widehat{E}[X]=h\left(U_{1}, U_{2}, \ldots, U_{n}\right)$.

The antithetic estimate of this should be:

$\widehat{E}[Y]=h\left(1-U_{1}, 1-U_{2}, \ldots, 1-U_{n}\right)$.

Understandably, the distribution of the two random variables above is the same and, concerning the covariance between the two variables:

$\operatorname{Cov}[\hat{E}[X], \widehat{E}[Y]]=\operatorname{Cov}\left[h\left(U_{1}, U_{2}, \ldots, U_{n}\right), h\left(1-U_{1}, 1-U_{2}, \ldots, 1-U_{n}\right)\right] \leq 0$,

if the $h$ function is monotonic. ${ }^{10}$

Its practical application is very simple. The $n$ sample unit needed for simulation is generated by taking $n / 2$ pieces from the even distribution and the rest are formed by consecutively subtracting these units from 1 . As a result, the variance of the estimation will be lower than if our variables were independent and the computing time will not increase either (moreover, subtraction is significantly faster than random number generation).

The antithetic variables method is a special case of the control variates method in which linear correlation is -1 , therefore the rate of variance decrease is the highest possible. In spite of the fact above, literature deals with the two methodologies separately.

$10 \mathrm{http}: / /$ www.ksh.hu/statszemle_archive/2012/2012_06/2012_06_521.pdf 


\subsection{Modelling of the exposure and cash flow of the Baby Loan by means of the Monte Carlo simulation}

Unlike the professional approach, considering certain demographic criteria as random variables, in our model, cash flows (CFs) were generated by simulation. $X_{t}^{(i)}$ indicates the cash flow of agreement $i$. in $t$ time. In the case of $m$ contracts, the cash flow of the loan at $t$ time is

$C F_{t}=\sum_{\mathrm{i}=1}^{\mathrm{m}} \mathrm{X}_{\mathrm{t}}^{(\mathrm{i})}$

The bank intends to indicate the CF process in advance, for the purposes detailed above. In this section, we describe how the problem of the estimation of $C F_{t}$ values can be approached.

A cash flow belonging to a client, i.e. $X_{t}^{(i)}$ is determined by the following:

- How do the interest rates change?

- Is there any prepayment?

- How many children are born? When are they born?

- Are there any divorces? If there are, when do they happen?

In the light of the above, in fact, process $X_{t}^{(i)}$ depends on 4 processes: the interest process ( $r_{t}$ : the current interest rate of the loan), the date of prepayment ${ }^{11}$ by the client $\left(\tau_{t}: t\right.$, if the client paid back all of their debts at the date indicated by $\mathrm{t}$, and it is infinite if no prepayment has been made), the number of children $\left(G_{t}\right)$ and the indicator of divorce $\left(D_{t}\right)$. If we know the aforementioned processes for client $i$. the process of repayment can be clearly recorded, i.e.

$X_{t}^{(i)}=f\left(r_{t}, G_{t}, \tau_{t}, D_{t}\right)$

where $f$ describes the conditions of the loan. The more parameters determine the process, the more justifiable it is to apply the Monte Carlo simulation. After generating the determining processes for each contract, we allocate the client's cash flow. In this way, we can generate independent samples taken from the same distribution, the average of which converges with the expected value of the distribution according to the central limit theorem.

11 Prepayment by the client and prepayment by the state are distinguished. Process $G_{t}$ clearly defines prepayment by the state. However, the model also takes into account that the client is entitled to prepay anytime. 
Of course, in practice, it is not worth generating all four processes stochastically. It would result in an overly complicated model, which may significantly increase run-time and the expected improvement and development based on the costbenefit principle would not be realised either. For example, in the case of the interest process, it could be a proper solution to use 5-year forward rates instead of generating a new process in each scenario, i.e. we calculate forward rates for the interest rate paths based on the spot yield curves, which enables transparent and reproducible simplification.

It is adequate and practical to incorporate voluntary repayment by the client and divorce deterministically into the model, as, regarding these one-time events, is enough to weight the cash flow by their probability. In the case of an interest-free loan, considering the time-value of money and the opportunity costs of other investments, prepayment by the client is not considered to be rational behaviour. Therefore, normally, this type of prepayment rate (voluntary and not dependent on any demographical event) paid by the state is $\% \%$. In the event of divorce, an important input of the model is the date of marriage. The algorithm sets the cumulative divorce probability corrected by the time elapsed between loan disbursement and marriage along trajectories.

If having children is involved, the stochastic approach cannot be avoided. The fact that the child is born within 60 months after the disbursement of the loan results in substantially different cash flow. Even if it happens, other factors matter, as well, such as when the child is born, whether and when the first child is followed by a second child and a third child etc. Therefore, it is not a good idea to allocate a trajectory describing a typical childbirth process to clients and calculate the relevant cash flow accordingly, as several market participants have tried to do it.

Insignificant divergence from the trajectory may lead to considerable difference in cash flow. (For example, if some clients are likely to have the first child in the 59th month, a one-month divergence from this timetable already excludes the couple's eligibility for the discounts. Meanwhile, if the first child is born in time, the loan may expire a few years later, as perhaps two additional children are born.) Compared to this, family planning might result in a considerably larger deviation.

Based on the above, the algorithm is as follows: We generate $n$ (pieces) of $G_{t}$ process, which refers to the number of children at a certain time $t$. The appropriate cash flow, weighted by the probability of divorce and prepayment, is allocated to this. By averaging the aforementioned scenarios, we receive the estimate for the expected value. 


\subsection{Accuracy of estimation}

We should not forget the accuracy of estimation either: how to choose the number of scenarios $n$ and the reliability function $n$ provides. Of course, the higher the value of $n$ is, the smaller the variation of the average. At the same time, the question arises: how can we establish the degree of variation if we do not even know the distribution? It can be prevented in two ways. Based on the first method, which we regard as less accurate, the model is run on a significantly high number of scenarios. This model is supposed to be close enough to real distribution, therefore its standard deviation can be considered to be the variation of real distribution. The problem with this theory is that we got into a vicious circle: how high should that "significantly high number" be?

Another approach to the examination of variation: analysing the samples, we examine which months typically have large standard deviation. Based on the definition, we estimate the variation for these moths, even if we cannot calculate it. The set of the client's possible instalments is indicated by $t$ at a certain time $F_{t}$. When

$E\left[\mathrm{X}_{\mathrm{t}}^{(\mathrm{i})}\right]=\sum_{f \in F_{t}} p_{f} \cdot f$,
$E\left[\mathrm{X}_{\mathrm{t}}^{(\mathrm{i})}\right]=\sum_{f \in F_{t}} p_{f} \cdot f^{2}$.

Of course, the main difficulty is recording probabilities. As an illustration, we record that our imaginary client pays a market instalment in the 65 th month. This situation is true when no child is born in the first 60 months and the debtors do not get divorced or when they get divorced in the preceding 64 months:

$p_{\text {market }}=\left(1-p_{v}\right)^{64} \cdot\left(1-p_{1}\right)^{60}+\sum_{i=1}^{64}\left(1-p_{v}\right)^{i} \cdot p_{v}$

It is essential to strive for a high-end estimate. Neither the probabilities of childbirth, nor the probability of divorce differ from each other significantly, therefore they can be substituted by a single rate to simplify calculation. The cash flow elements can be drawn together, as well: e.g. in the case of a client, for the 65th month, the cash flow can be o if the first child was born within 3 years, but prior to the 60 th month, it can be HUF 50,000 + interest rate (it is already a high-end estimate) if the loan remained discounted, it can be HUF 120,000 if it was converted to a market loan, or HUF 3 million or HUF 10 million respectively if a second or a third child was born. Of course, these are very conservative high-end estimates, 
but by means of such (if necessary fine-tuned) estimates, the variation can be estimated (even by taking into account the aforementioned noise reduction models). Even if the result we get for $\operatorname{Var}\left[\mathrm{X}_{\mathrm{t}}^{(\mathrm{i})}\right]$ is acceptable, the most difficult task is still left. If the sample average $-\overline{X_{t}(i)}-$ is normal distribution, it can be stated that the model works with a $5 \%$ relative standard error at a confidence level of $95 \%$ if

$P\left[-5 \%<\frac{\overline{X_{t}(i)}-\mu}{\sigma}<5 \%\right]>95 \%$,

i.e.

$5 \% \cdot \sqrt{n}>1,96$.

However, according to the central limit theorem, the distribution of the sample average only converges with the normal. The speed of convergence also depends on $n$. The results of its measurement have not proven to be useful in practice so far. ${ }^{12}$ The aforementioned classic procedure can be used if, for example by goodness of fit test, we can ascertain that the sample average is of normal distribution.

Finally, we would like to draw the readers' attention to another fact related to the required scenario number. If we consider only one client, the result for a given month might even be an unrealistic cash flow unit, e.g. HUF 5.5 million. It may remind us of the "fairy tale of statisticians" in which the statistician is hunting for a rabbit. The likelihood that his gun will fire to the right or to the left at a $45^{\circ}$ angle is $50 \%$. If he is aiming exactly at the rabbit, he is going to hit it according to the expected value, however, in practice, he will stay hungry. Such values will not be smoothed by the high scenario number, but rather by the high number of contracts. In view of the above, getting enough clients will help us. In this case, the scenario number can be decreased.

12 The available theoretical results include the Berry-Esseen theorems. However, putting them into practice is very circumstantial. 


\section{Figure 1}

The cash flow of Baby Loan repayments for 50 notional clients, 10 (in the figure above) and 200 scenarios (in the figure below)
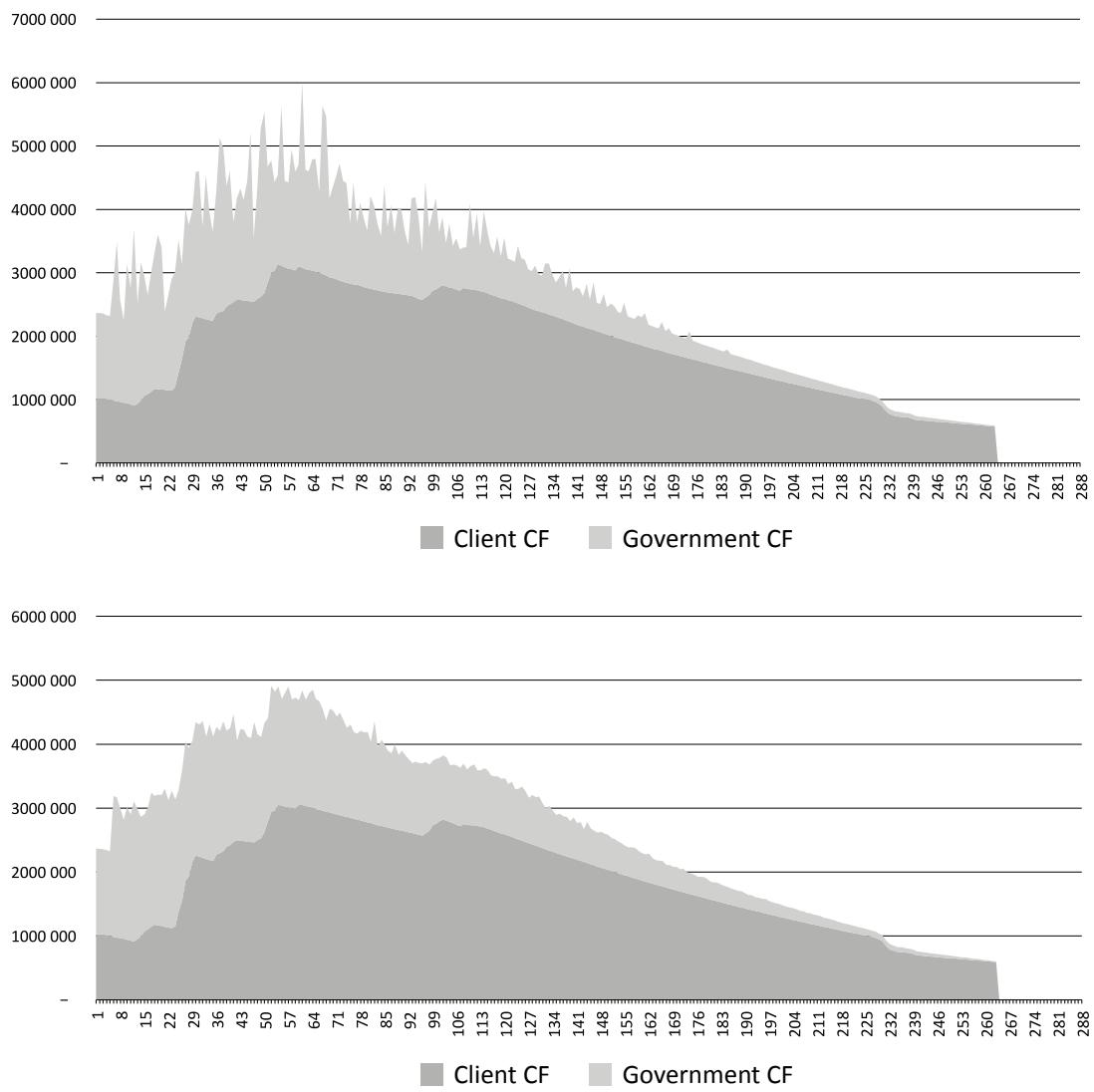

The two figures represent the outputs of the model run on 50 randomly generated notional contracts. In the left figure, we ran 10 scenarios per client, while in the right figure, 200. It is conspicuous that the client cash flows were very similar in both cases, while the state's cash flow, which consists of interest rates and prepayments, was extremely "spiky" when 10 scenarios were applied and 200 scenarios could not smooth it either. It clearly shows that the loan's cash flow could be made smoother by increasing the number of clients, as variation would still be very high for 50 clients. 


\subsection{The estimation of demographic parameters}

In Hungary - but perhaps in the world ${ }^{13}$ - Baby Loan is the first loan whose cash flow primarily depends on demographic parameters, such as childbirth or even divorce. Consequently, a new chapter will be dedicated to the estimation of their distribution.

As we explained in the previous chapter, in the case of divorce, we estimated a monthly survival curve deterministically integrated in the model, based on the data provided by the Central Statistical Office ${ }^{14}$. In order to incorporate the frequency of divorces and the survival curve in the model, we must decide whether we intend to apply some kind of shock according to the tendencies observed or, based on our current knowledge, we do not distinguish marriages contracted before and after the launch of the Baby Loan.

We have also mentioned that a record number of 65,268 marriages were contracted last year (more than 41,00o in the second half of the year), while the average number of marriages was about 51,00o between 2016 and 2018. Although the spike in the number of marriages coincides with the launch of the Baby Loan, currently, we cannot tell the percentage of marriages which were officially advanced and the percentage of marriages regarding which the couple hurried. In the light of the foregoing, based on our current knowledge, it cannot be clearly stated that these marriages differ from earlier trends regarding their expected length. Consequently, in our opinion, we need to calculate with the observable divorce rate in a conservative manner and later correct the result if necessary.

If we break down the 26,792 marriages contracted in the first half of 2020 by year in a linear manner, we get 54,000 marriages, a figure typical of previous years. 24,000 marriages were contracted in Hungary in the first half of 2019, while we do not know the number of marriages delayed to the second half of 2020 due to the COVID-19 pandemic. Therefore, we cannot make an exact conjecture about the willingness to marry for the year 2020 .

13 It cannot be excluded that a similar loan exists, however, the authors have not found any relevant descriptions in the foreign press.

14 KSH (2019): A válások demográfiai jellemzői [The Demographic Features of Divorces]. Statisztikai Tükör, 28 March (http://www.ksh.hu/docs/hun/xftp/stattukor/valas17.pdf). 


\section{Figure 2}

The number of marriages per thousand people and their 3-year moving average

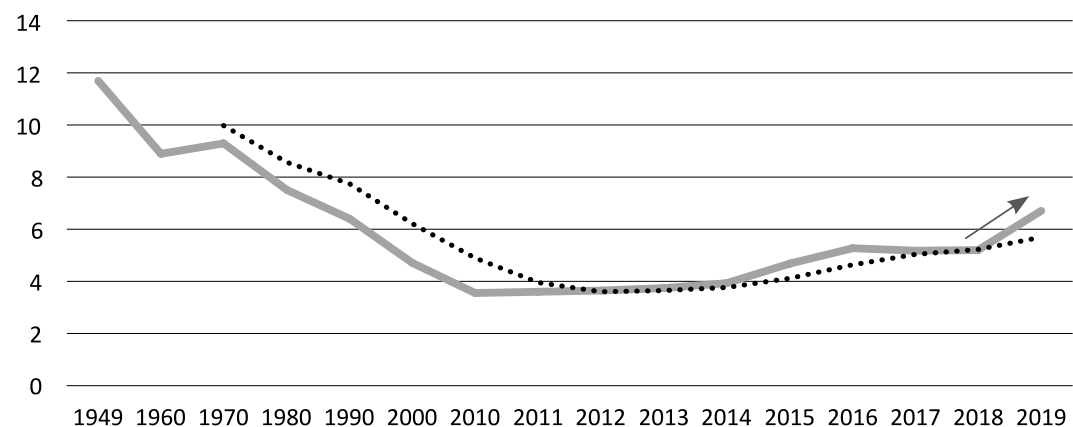

Source: KSH

In some respects, having a child is a conscious decision, therefore at first sight it might appear that it is a good idea to observe trends within certain social groups and use them for cash flow modelling. However, there is not enough available data for preparing such statistics. Moreover, we cannot be certain that such trends exist, as sometimes even the most conscious family planning is affected by incidents (infertility, financial situation etc.). Until the generation of a sufficient amount of data of proper quality for such examination, the calculation of the distribution of process $G_{t}$ is unavoidable. As the total fertility rate indicates, the change in childbearing willingness has been relatively stable over the past 4-5 years, remaining under 1.5, drifting apart from its lowest point in 2011 (1.23), but still under the EU-28 average, where childbearing willingness is very high in the Baltic, Scandinavia and France.

\section{Figure 3}

The change of fertility rates in Hungary and in the EU

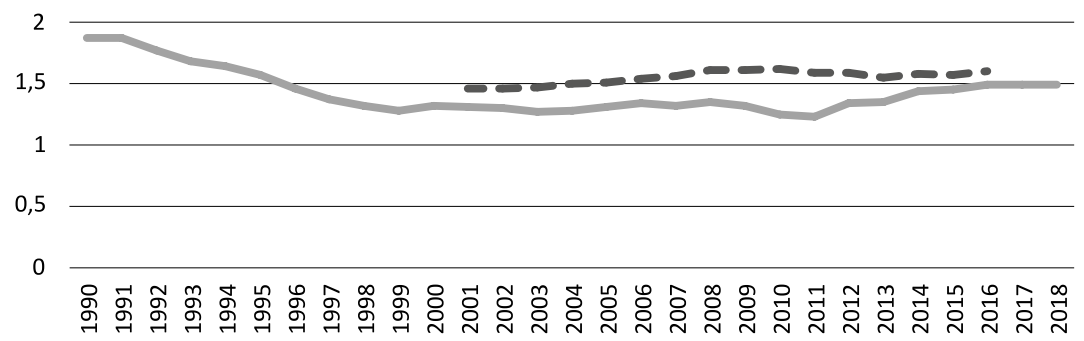

$$
- \text { Hungary }
$$

Source: KSH, Eurostat 
As the figures above still do not reflect the potential incentive effect of the Baby Loan, when calculating the distributions on which the simulation is based, we can rely on recently stabilised levels. At the same time, it is important to review the starting parameters on an annual basis and add some bank- and portfoliospecific data.

The $t$ time index has indicated the time horizon of repayment so far so that it can be in accordance with the cash flow index. However, the date of birth of a child obviously does not depend on this. In terms of the estimation of the probability of childbirth, the simplest segmentation is conducted based on the mother' age and the child's ranking ${ }^{15}$. As we mentioned earlier, our current statistics cannot be thoroughly substantiated. On the other hand, the stochastic character of family planning is primarily given by the mother's fertility. Considering natural biological processes, classification by age and the ranking of the child is definitely justified.

Based on specific experience of the bank, it is sometimes worth considering and revising other segmentation possibilities, as well (e.g. income, the parents' education, geographic segmentation or segmentation by the type of settlement, etc.). According to our current data, the majority of applicants are intent to have a child $^{16}$, therefore based on the national data, further segmentation would not lead to a better result. However, banks may further segment the parameter tables under continuous back-testing.

In the light of the above, we examine the $G_{k}^{*}$ stochastic process that indicates how many children a women has at the age of $k$. The trajectory of this process is an increasing monotonic step function with steps of 1 . (If we consider births of twins, the latter condition is not prescribed. However, the probability of this is negligibly low, as the model would be more complex and would require extra resources, which would not be in proportion to additional utility ${ }^{17}$.)

As far as stochastic scenario generation is concerned, it is enough to calculate $P\left(G_{k}^{*}=i \mid G_{k-1}^{*}=i-1\right)$ conditional probabilities. As we have already mentioned several times, until a bank does not have own experience, such values can be estimated on the basis of national statistics. Later, it is recommended that the figures be corrected by own statistics, which can already consider autoselection, i.e. whether the borrowers' expected willingness to have children is higher than the national average.

15 Child ranking refers to the place of the child in the birth order.

16 Most couples apply for the loan either during pregnancy, or when they are at a stage of life in which the first child is typically born.

17 Our data referring to the rate of twin births is $32.2 \%$. Source: KSH (2014): Statisztikai Tükör 8(9). 
According to the other method, the periods between childbirths are modelled and the $\tau_{1}, \tau_{2}, \ldots$ markings are introduced, where $\tau_{i}$ refers to the time until the birth of the $i$. child. In this case, $G_{k}^{*}=\sum \chi_{\left\{\tau_{i}<\mathrm{k}\right\}}$.

In the realised model, in the course of simulation, the remaining cash flows are recorded for each remaining date ${ }^{18}$, depending on demographic variables. Based on these records, statistics on trajectory and profitability are made. The model is suitable for the scenario-level evaluation of individual loans, but it is suitable for carrying out portfolio-level evaluations based on portfolio-level aggregate data, as well.

In the model, the CF runs are broken down by risk, which enables the calculation of the present value that also takes different risk profiles into account. In other words, the model know that, depending on a given variable, what percentage of the CF the debtor would pay and what percentage the government grant would be. All this is shown from the creditor's, i.e. the bank's point of view.

Based on the expected cash flows calculated in this way, by means of the appropriate discount factor, the fair value of the portfolio can be determined. The fair value of the portfolio may fluctuate in time owing to the effect of the items both in the numerator (CF values depending on demographic processes and interest payment cash flows related to the yield curve) and in the denominator (discount factor with risk premium components).

\subsection{Questions regarding implementation}

Appropriate implementation is as important as appropriate methodology, as we would like to use the model on a regular basis in time-critical processes (monthly and quarterly closing, surveillance reports, etc.).

As a leader, it is easy to make the mistake of commissioning modellers whose priority is often not the smooth operation of the entire process, but a personal preference for a specific platform, convenience or personal ambition instead to plan the architecture of implementation. Of course, consultation with the modellers is very important, but several other factors have to be considered when selecting the platform of implementation:

- The model has to run within reasonable time, leaving some buffer time for possible re-run(s) and sensitivity analyses, as well.

18 The remaining time may increase, e.g. due to a suspension of 36 months, or may decrease due to equity release. 
- Any changes to the model should be made in the simplest and fastest way, with minimum probability of error.

- Any changes to the model and the runs should be documented (version control, audit trail).

- In the labour market, it should be easy to hire appropriately qualified professionals for the maintenance of the model. It is not worth building a complex model on strictly cost-benefit basis, as it may lead to "knowledge monopoly".

- The routine operation ("running") of the model should be the least complex and manual process possible and should fit well into standard operating procedures.

Fundamentally, implementation can be carried out on the following platform:

- MS Excel: its advantages include the fast transfer of changes and the large user/developer base; its disadvantages include the inappropriate audit trail, the lack of change tracking, circumstantiality and slowness.

- R, Python: both are popular programming languages, which contain a lot of function libraries. Due to interpreted language, it is not the fastest, but allows fast development time, saving translation and development time.

- Java, .NET (C\# or VB): programming languages translated to intermediate code, with a wide user base and functions, the performance of which is between interpreted and translated (e.g. $\mathrm{C}++$ ) languages, providing an optimal compromise. The .NET environment has very good interoperability with the MS Office package, therefore the input and output data of the simulations can be written even in Excel format.

- Enterprise environments (e.g. SAS, SAP, SQL Server, Oracle etc.): regarding change tracking, audit trail and performance, it is perhaps the best choice, but the maintenance of the model may be more circumstantial owing to the overhead of IT processes.

As far as supervision and operation are concerned, it is worth considering the operation of a parallel architecture, i.e. the parallel development of a so-called "prototype" model and a live "production" model. In the event of changes to the model, the advantages of the prototype model are rather its transparency and easy changeability, due to which it is easier to implement the changes in live systems. 


\section{CONCLUSION}

The fundamental similarity between the banking sector and the insurance sector is that both of them organise risk pooling (for loan and insurance risks, as well as jointly for market risks). In spite of this fact, with a few exceptions, risk management and modelling practices have had very different paths.

The practice that has developed (even got established) to date has strengths and weaknesses on both sides.

A positive element of the insurance sector's practice is the extensive use of monthly contract-level CF projections, while its weaknesses include rough-and-ready asset-side and macro modelling.

On the side of banks, strengths include the powerful macro-modelling background and the sophistication of evaluation on the asset side. At the same time, in the monthly modelling of the cash flow of more complex contracts, there are still possibilities for the improvement of the current heuristics on both the asset side and the liability side.

Fortunately, in the regulation of the two sectors, a kind of convergence has been observable for a while, see: the pillars of Basel III and Solvency II or the consistent application of the IFRS9 for investment contracts posing no significant insurance risk instead of the fairly liberal IFRS4, which inevitably put the development that has been rather diverging so far on a similar path. Nevertheless, in our view, both the banking sector and the insurance sector could benefit a lot from the modelling and risk management techniques applied by the other sector for basically similar problems.

We believe that by means of the novel cash-flow estimation approach described above a model which is also optimal regarding cost-benefit and is suitable for the risk management purposes of the bank and for the calculation of accounting fair value can be set up, creating harmony between two objectives, which unfortunately does not come true in many other cases. The model considers several aforementioned factors in the course of the estimation of cash flows, thus increasing its reliability and accuracy. However, it is not too complex, therefore professionals with general mathematical-statistical and economic knowledge can maintain it and interpret the results easily. Furthermore, it is in accordance with the general requirement set by the supervisory authority obliging banks to use professionally well-founded models instead of expert estimates. Although these models should not be "black-box"-like, i.e. the operation of the model should be transparent and clear both for the users and the supervisory authority

Basically, we, the authors are practitioners, therefore it is possible that we did not pay attention to better-known methods described in professional literature and 
did not necessarily choose the most perfect solution. The statistical and modelling toolkits described in the article separately cannot be called radical innovation. The novel feature of our article is that we have combined the estimation and modelling techniques, which were already well-established in other sectors, for solving problems related to the Baby Loan. It is a fact that questions regarding the modelling of and risk management related to Baby Loans are still unanswered, but, based on experience, methodology will become more structured. We hope that our article can be the first important step into this direction.

\section{REFERENCES}

ECKHARdt, Roger (1987): Stan Ulam, John von Neumann, and the Monte Carlo method. Los Alamos Science 15 (Special Issue), 131-137.

KeHL, DÁNIEL (2012): Monte-Carlo-módszerek a statisztikában [Monte Carlo Methods in Statistics], Statisztikai Szemle 9o(6), 521-543.

Kennedy, Tom (2016): Monte Carlo Methods - a special topics course. The University of Arizona, 27 April, https://www.math.arizona.edu/ tgk/mc/book.pdf.

KSH (2014): Ikerszületések Magyarországon [Twin Births in Hungary]. Statisztikai Tükör 8(9), https://www.ksh.hu/docs/hun/xftp/stattukor/ikerszul.pdf.

KSH (2019): A válások demográfiai jellemzői [The Demographic Features of Divorces]. Statisztikai Tükör, 28 March, http://www.ksh.hu/docs/hun/xftp/stattukor/valas17.pdf.

MÉLARD, GUy (2010): On the accuracy of statistical procedures in Microsoft Excel 2010. Computational Statistics 29, 1095-1128.

Tarbell, Thomas F. (1934): Incurred But Not Reported Claim Reserves. Proceedings of the Casualty Actuarial Society XX, 84-89, https://www.casact.org/pubs/proceed/proceed71/71083.pdf. 